measured 29 inches. There was an obscure sense of fluctuation in the abdomen, but on a puncture being made in the linea alba, not more than a pint of a dirty serous fluid escaped. On laying open the abdomen, the omentum was found to be thin, elongated, of a dark purple colour, and covering an immense encysted tumour of an irregular globular form: on throwing the omentum upwards, the descending colon was found to adhere firmly to the front of the tumour, being pushed forward out of its natural situation, and it proved to be the thickened cord alluded to above. The hand was now passed over the face of the tumour to the left, when it met with resistance at the extremities of the false ribs, from which point the peritoneum was reflected over the tumour, to which it firmly adhered, as if forming the outer tunic of the sac, and was traced round to the lumbar vertebræ, to which it was firmly attached, the small intestines being pushed upwards into the right hypochondrium, so that the tumour actually filled the whole of the abdomen, with the exception of the epigastric and right hypochondriac regions, as already stated. An incision was now made through the peritoneum at its point of adhesion to the ribs, the hand introduced, and the tumour pulled over to the right side, it having no connexion with the lumbar region, or psoas muscle, excepting through the medium of the loose cellular substance; it was, however, firmly bound down to the right side of the lumbar vertebra, so that this point and the extremities of the ribs were the points of attachment, the tumour occupying the whole of the intermediate space. Not a vestige of the left kidney or mesenteric glands was visible. The tumour, on being removed, weighed $9 \frac{1}{2}$ lbs., and contained a soft, pulpy, whitish coloured mass, resembling the medullary portion of the human brains, mixed with a dirty reddish-coloured fluid, a portion of which mass I supposed to be the seat of the kidney, from its reddish-grey colour and radiated appearance resembling the tubulæ of that viscus. There were several tubercles in the liver, containing a brain-like substance, in the centre of which was a small quantity of reddish fluid. The left lung was composed of solid masses of tubercle, each the size of a large turkey's egg, and containing the same kind of soft brain-like mass as that found in the tubercles of the liver.

The subject of this formidable disease was a black, about twentynine years of age, a native of Madagascar, by trade a carpenter, the slave of Mr. Bule, of Mahebourg, who gave the following history of his case:-He stated that about eighteen months prior to his being sent to hospital, a small sore, not larger than a herring scale, made its appearance on the sole of the left foot, to which numerous remedies were applied with no good effect; that an ungovernable fungus formed, which daily increased, and at the period of his admission into the hospital, on the 8 th of July, 1827, was as large as a common-sized cauliflower, which it resembled in the rough tuberculated appearance of its surface, but was of a deep livid colour, approaching to blue. The foot was much deformed by numerous tubercles, resembling the mulberry fruit; there were also numerous enlarged glands extending from the inner ancle, following the course of the vena saphena to the groin. The inguinal glands were very much enlarged, one being the size of an orange, the integuments covering it of a mottled blue colour. Bowels torpid, health in other respects apparently good, spirits remarkably so. Tumour but little sensible, excepting when a probe was introduced between the tubercles, which produced hæmorrhage, to attacks of which it had been subject.

From this period numerous remedies were applied, as well constitutional as local. The bowels became more regular, but the other symptoms increased, and notwithstanding that the removal of the diseased parts by extirpation appeared to all who saw him the sole chance of saving the man's life, yet he obstinately refused to submit to an operation until the 6th of August, when I amputated below the knee, in the presence of several medical gentlemen. Diseased glands, of a black colour, and hard, firm texture, were discovered, in the course of the operation, situated in the cellular substance, and were removed. The gland in the groin had much increased in size, but the patient would not submit to its removal. The following were the dimensions of the tumour of the foot when removed:-viz., Circumference round the extremities of the toes, sixteen French inches; from the great toe to the little one underneath, twelve and threequarter inches; at the dorsal bones, twelve and three-quarter inches; the diameter of the tumour, which was of a circular form, eight inches, and its depth, (on an incision being made, separating the great and second toes, four inches. The surface exposed by this incision resembled the kidney of an ox, but was of a deeper livid colour, and appeared as if composed of a consolidated mass of tubercles, the striated lines of separation being very distinct. The cellular substance beneath the integuments was at least an inch in thickness, firm in texture, and of a purple colour, extending as high as two inches above the ancle, where the bones were sawed across, to admit of the more easy preservation of the preparation, in order to its being sent to England. From this period the glands in the groin went on increasing in size; yet the stump healed kindly, and was perfectly cured by the 10th of September. On the 24th of October, the gland in the groin had increased to the size of a six-pound shot; a small piece of the integuments on its centre sloughed, but this was not followed by a discharge of matter. The ulcer thus formed resembled an issue made by caustic alkali, but continued gradually to increase in size until it became four inches in diameter, exposing the cellular substance in a sloughing state, forming a most offensive ugly ulcer. Emollient poultices, mineral acids, oil of turpentine, and other detergents and styptics, were alternately applied without the least good effect; an hæmorrhage, to which the wound became subject, was, however, invariably arrested by the latter application. Soon after the formation of the ulcer in the groin, small hard moveable bodies began to make their appearance under the skin in different parts of the trunk and extremities, gradually increasing in size, with a corresponding emaciation and debility, until three o'clock on the evening of the 23rd of January, 1828, when the patient expired. The odour emitted from the ulcer for nearly a month prior to his death was most offensive. The body was inspected the following day, at noon, in the presence of the gentlemen who witnessed the amputation, and who appeared much interested in this extraordinary case. The following were the appearances which presented themselves on dissection:-The ulcer in the groin was four inches in diameter, of a circular form, having a solid elevated margin of two inches in thickness; its surface was covered to the depth of an inch with disorganized cellular substance, beneath which was a solid brainy-looking mass, two inches in thickness, and of the size and form of the ulcer. This brainy substance seemed to be connected with a black firm mass of either cellular substance or diseased consolidated glands, extending to three inches above Poupart's ligament, terminating in a black-coloured mass, the size of a large orange, and containing a fluid resembling that of a cuttle-fish. The abdomen, when laid open, struck all present with astonishment. The cellular substance, posterior to the peritoneum, was thickly studded with small black moveable glandular bodies, about the size of the common garden pea; similar bodies were observable in the cellular substance beneath the pleura. The omentum was equally filled with them, many hanging pendulous; mesenteric glands much enlarged. The liver was also enlarged, of a dark colour, and weighed six pounds; its surface thickly studded with tubercles, some the size of a walnut, others smaller; its substance when cut into seemed as if composed of a solid mass of tubercles. No apparent change in the structure of the stomach or intestines; kidneys elongated and unusually soft; spleen in its natural state; pancreas enlarged; lungs adherent generally ; right one solid, small, and tuberculated ; the anterior surface of left of a marble grey colour, and beautifully spotted by small bodies resembling black feathers; posteriorly, the lung adhered to the pleura costalis, and was thickly tuberculated. The pericardium contained a large quantity of a turbid yellow-coloured serum. The surface of the heart was covered with tubercles, and its structure so completely changed, that, when removed from the body, it was difficult to distinguish it as a heart. The os innominatum, with a few inches of the thigh bone, and such portion of the soft parts as were considered necessary to shew the relative situation of the disease in the groin, were removed, forming a beautiful preparation. The liver, lungs, and heart, were also removed, forming an equally beautiful preparation, but it is to be regretted that the heat was so intense, (thermometer $88^{\circ}$ in the shade,) and rectified spirit so scarce, that both specimens were totally destroyed, arrack, in which they were immersed, being too weak to preserve them.

Civil Hospital, Grand River, Mauritius.

\section{REMARKS ON THE COMPOUND NATURE OF CARBON.}

By Prmip B. Ayres, M.D., Lecturer on Chemistry at the Charing Cross Hospital.

Two communications of a very singular character have appeared in The LanceT for September 21st and 28th, in which the writers endeavour to make it appear that carbon is a compound substance. A work by Mr. Rigg is also advertised, bearing the title of "Researches, Chemical and Agricultural," which is occupied by the demonstration, "that carbon is a compound substance, made by plants in quantities varying with the circumstances under which they are placed." Mr. Rigg, in his paper 
in The Lancet, has endeavoured to extend this formative power to animals, and gives some experiments which he thinks countenance his opinion. Now, although I would by no means deny that carbon, or any of what are now called elements, may be really compounds, yet we must have good and sufficient evidence that they are compounds before we can admit that they are so. A short time since we heard that boron and silicum were mutually convertible! We now hear that carbon is a compound, but are left in the dark as to its elements. When it is asserted that a substance is compound, we certainly have a right to expect that its elements should be either isolated and exhibited; or when, as in the case of fluorine, they cannot be so isolated, we expect, at the least, that their existence should be rendered probable. But although the carbon is said by $\mathrm{Dr}_{\mathrm{r}}$. Aldridge and Mr. Rigg to be made by plants, and by Mr. Rigg to be secreted by animals, neither of these gentlemen have been kind enough to tell us what the carbon is made or secreted from; or, in other words, what is its source?

With these preliminary remarks, proceed we to examine the experiments on which this rather strange assertion is founded. And first, of Dr. Aldridge. The note of Dr. Aldridge is headed, "Carbon a Compound Body made by Plants;" but I am at a loss to conceive how the compound nature of carbon can be asserted from the contents of that paper! The experiments of Dr. Aldridge simply shew that carbonic acid is sometimes decomposed, and the carbon deposited in the plant, without the agency of much light. His experiments are given in so vague and general a manner as to throw an air of uncertainty over them. We are told that the carbon of half a pound of grass, kept in water fourteen days, either exposed to the light or in perfect darkness, had increased its carbon over and above a similar weight of fresh grass. We are not told whether this grass was gathered, or remained attached to the roots, nor whether, during its long immersion in water, it had lost its vitality, and undergone the putrefactive fermentation, which I should imagine was the case. If putrefaction had taken place, of course the proximate principles of the grass had undergone a change of composition, which would render the results fallacious.

Dr. Aldridge's second experiment, in which he caused an equal weight of beans to grow in perfect darkness, and others exposed to the light for a month, and found that in each case the carbon was greater than in the same weight of beans that had not germinated, is liable to the objection that it is very doubtful whether the plants would be found alive at the end of the month if light was perfectly excluded. But even if vitality remained, and the carbon was increased in weight, the experiment merely proves that the assistance of light is not absolutely necessary to the decomposition of carbonic acid by plants. The experiment with lemna minor, where oxygen was given off in total darkness, proves nothing more than the former experiments-the decomposition of carbonic acid gas without the assistance of light, or, at all events, of much light, not that carbon is made by plants. Mr. Rigg, in his observations on the manufacture of carbon by animals, sets out with the supposititious case that an animal, containing fifty grains of carbon, consuming other fifty grains in the shape of food during a given time, should, during the same time, give out sixty grains, and finally yield sixty grains on incineration, whereby an increase of twenty per cent. of carbon would occur, which Mr. Rigg says can only be accounted for by the secretion of carbon by animals. He decidedly states that he has repeatedly observed this increase in the amount of carbon. But how are the experiments condrcted on which such a conclusion is founded? He takes two small young animals, kills and dries one, and aseertains the amount of its carbon. He next feeds the other for some days with food, the composition of which is known, and at the same time placing the animal in a limited atmosphere, which is changed every two or three hours, ascertains the quantity of carbonic acid formed by respiration. Finally, the animal is subjected to the same treatment as the former one. This mode of experimenting is liable to very serious objections; first, there is the comparison of the two small animals, which, although apparently of the same size, may differ, to a considerable extent, in composition; and secondly, there is still some liability to error in the ultimate analysis of animal substances, which is, in truth, a very complicated and delicate manipulation; and thirdly, a larger number of analy ses are necessary in organic chemistry to arrive at a satisfactory mean.

The favourite experiment of Mr. Rigg was on a mouse, which, weighing two hundred grains, contained from twenty-five to thirty grains of carhon. This mouse being fed with sixty grains of bread daily, containing about sixteen grains of carbon, yielded twenty to twenty-six grains of carbon in the shape of carbonic acid by respiration. Mr. Rigg, however, does not tell us what was the amount of carbon ultimately existing in the mouse; nor does he inform us how often the experiment was repeated, nor from how many data he drew his conclusion. Mr. Rigg says, further on, that either of these animals may be kept without food until they give off, by respiration, a weight of carbon equal to eighty per cent., and retain, at the same time, sixty to seventy per cent. of that which they comprised at the commencement of the observation, shewing, says Mr. Rigg, that a weight of carbon equal to forty per cent. has been secreted.

I confess I am at a loss to understand what Mr. Rigg means here by secretion; he has stated that an animal kept without food excretes a quantity of carbon by respiration, which, together with what is found in the body after death, exceeds very greatly what the animal originally contained, and, therefore, that carbon is secreted. Perhaps, Mr. Rigg thinks that carbon is produced by a sort of spontaneous generation! but until Mr. Rigg is able to bring forward more convincing proofs of the spontaneous generation or manufacture of carbon, we must be allowed to adhere to the old adage, "Ex nihilo, nihil fit."

The ordinary estimate of carbon expired as carbonic acid is probably much too high when stated at from 5000 to 6000 grains per diem, amounting, as it would, to about three quarters of a pound avoirdupois. Mr, Rigg, taking this estimate, analyzes a number of the ordinary articles of food, gives us their proportionate amount of carbun, and finally presents us with a table of the quantities of different articles of diet necessary to make up the six thousand grains of carbon, and a most generous diet table it certainly is. He then calculates the amount of carbon in the diet of prisons, penitentiaries, and worlshouses, and finds the amount of carbon in the food very much below 6000 grains, and hence he again concludes that carbon is secreted to make up the deficiency. The diet table given by Mr. Rigg shews in how shocking a manner our poor are treated in many of our union workhouses, when we find that the diet of prisons is preferable to that of workhouses.

In all cases, Mr. Rigg finds that the carbon excreted by the respiratory process alone, not taking into account that contained in the urine, is greater than that contained in the food, and that the difference is increased by exercise. This sounds well for Mr. Rigg's theory,-but where does the carbon come from? -out of what is it made? Surely it cannot be made out of nothing! What other substance is converted into carbon, and if compound, what are its elements? These questions must be answered before we can admit that carbon is a compound sub. stance, or a substance made by plants.

12, Howland-street, Fitzroy-square, Oct. 4th, 1844.

\section{THE HYDRATED PEROXIDE OF IRON AN} ANTIDOTE FOR PRUSSIC ACID.

By Thomas Underhill, Esq., Surgeon, Great Bridge.

IN the last two numbers of The Lancex I have read reports of cases of poisoning by arsenic successfully treated with the hy. drated peroxide of iron. This remedy has, I believe, been employed with great success for the last ten years, and yet there are many who now doubt its powers as an antidote. In order to convince those who are still sceptical, we should endeavour to bring forward all the evidence in our power; and with that view, I send for publication the results of eleven cases which have occurred under my own immediate observation during the last three years; for in this, as in all other disputed points connected with medicine, experience is the graud basis upon which to found our arguments.

The first case presents some rather remarkable peculiarities, the symptoms differing in many respects from those generally observed in cases of arsenical poisoning. They bear some analogy to that class described by Christison as his seeond variety, which, as that author observes, are generally produced either by taking a large quantity of the poison, or by taking it in a state of solution.

The subject of this case had taken, as he admitted, nearly two table-spoonfuls (two pennyworth) of arsenic, mixed in about a pint of water. When called to him, I found him lying on the floor, in a state of syncope; pulse imperceptible; skin covered with a cold perspiration, with occasional convulsive tremors of the limbs, but no sickness. In a short time slight re-action came on, when, the stomach-pump not being at hand, I commenced giving the hydrated peroxide of iron, which I had carried with me, in large and frequently repeated doses. On the arrival of $\mathbf{M r}$. Davis (a surgeon living in the neighbourhood) with the stomachpump, we immediately proceeded to use it, and well washed out the stomach by the injection of successive quantities of warm milk and water. In a few hours, symptoms of inflammation of the stomach began to present themselves, but these soon yielded to the ordinary antiphlogistic treatment. 